\title{
Assessment of tissue distribution and concentration of $\beta$-cryptoxanthin in response to varying amounts of dietary $\beta$-cryptoxanthin in the Mongolian gerbil
}

\author{
Michael R. La Frano ${ }^{1,2}$, Chenghao Zhu ${ }^{3}$ and Betty J. Burri ${ }^{1,2 *}$ \\ ${ }^{1}$ Western Human Nutrition Research Center, USDA-ARS-PWA, 430 West Health Sciences Drive, Davis, CA 95616, USA \\ ${ }^{2}$ Department of Nutrition, University of California, Davis, CA 95616, USA \\ ${ }^{3}$ Department of Food Science and Technology, University of California, Davis, CA 95616, USA \\ (Submitted 23 May 2013 - Final revision received 12 September 2013 - Accepted 13 September 2013 - First published online 11 November 2013)
}

\section{Abstract}

There is a general lack of knowledge regarding the absorption and tissue storage of the provitamin A carotenoid $\beta$-cryptoxanthin. The present study investigated the whole-body tissue distribution of $\beta$-cryptoxanthin in an appropriate small animal model, the Mongolian gerbil (Meriones unguiculatus), for human provitamin A carotenoid metabolism. After $5 \mathrm{~d}$ of carotenoid depletion, five gerbils were euthanised for baseline measurements. The remaining gerbils were placed in three weight-matched treatment groups ( $n$ 8). All the groups received $20 \mu \mathrm{g} / \mathrm{d}$ of $\beta$-cryptoxanthin from tangerine concentrate, while the second and third groups received an additional 20 and $40 \mu \mathrm{g} / \mathrm{d}$ of pure $\beta$-cryptoxanthin (CX40 and CX60), respectively, for $21 \mathrm{~d}$. During the last $2 \mathrm{~d}$ of the study, urine and faecal samples of two gerbils from each treatment group were collected. $\beta$-Cryptoxanthin was detected in the whole blood, and in twelve of the fourteen tissues analysed. Most tissues resembled the liver, in which the concentrations of $\beta$-cryptoxanthin were significantly higher in the CX60 (17.8 (sEm 0.7) $\mu \mathrm{g}$ /organ; $P=0.004$ ) and CX40 (16.2 (SEM 0.9) $\mu \mathrm{g} /$ organ; $P=0.006$ ) groups than in the CX20 group (13.3 (SEM 0.4 ) $\mu \mathrm{g}$ / organ). However, in intestinal tissues, the concentrations of $\beta$-cryptoxanthin increased only in the CX60 group. Despite elevated vitamin A concentrations in tissues at baseline due to pre-study diets containing high levels of vitamin $\mathrm{A}, \beta$-cryptoxanthin maintained those vitamin A stores. These results indicate that $\beta$-cryptoxanthin is stored in many tissues, potentially suggesting that its functions are widespread.

Key words: $\beta$-Cryptoxanthin: Tissue distribution: Gerbils: Carotenoids: Vitamin A: Retinol

$\beta$-Cryptoxanthin is a provitamin A carotenoid found in high concentrations in tangerines, oranges, papayas and red sweet peppers ${ }^{(1)}$. In addition to its vitamin A-forming capabilities, $\beta$-cryptoxanthin may have other beneficial functions. It possesses antioxidant activity ${ }^{(2)}$, and animal studies have indicated an ability to reduce tumorigenesis in several different organs $^{(3-6)}$. Furthermore, $\beta$-cryptoxanthin has been postulated to have a role in bone formation ${ }^{(7)}$.

Although it is one of the most commonly consumed carotenoids ${ }^{(1)}$, there is relatively little known about its metabolism. $\beta$-Cryptoxanthin can effectively improve long-term vitamin A status in animals ${ }^{(8)}$, and probably in humans ${ }^{(9)}$. Studies on comparisons of estimated dietary intakes with plasma concentrations have shown that $\beta$-cryptoxanthin appears to have greater bioavailability than $\alpha$ - and $\beta$-carotene in humans ${ }^{(10,11)}$. $\beta$-Cryptoxanthin micellerisation in the intestine has been shown to be 3 -fold higher than $\beta$-carotene ${ }^{(12)}$, presumably due to its higher polarity. Also, it is more effectively dissolved in lipid droplets in the chromoplasts of fruits than carotenoids bound to the chloroplasts of green leafy vegetables ${ }^{(13-15)}$.

A whole-body assessment of $\beta$-cryptoxanthin absorption, including the testing of multiple biological tissues in response to its increased intake, has not yet been performed. Such a study can provide better understanding of its metabolism and where it may have functional benefits. To date, most research on $\beta$-cryptoxanthin has used animal models that do not metabolise carotenoids similarly to humans ${ }^{(16,17)}$. It is important to study an appropriate small animal model of carotenoid metabolism, whose results can be more easily translated to humans. The Mongolian gerbil appears to be the best small animal model available for human provitamin A carotenoid metabolism ${ }^{(18,19)}$, primarily because they absorb carotenoids intact and are able to convert provitamin A carotenoids to vitamin $\mathrm{A}^{(20)}$.

Abbreviations: CX20, gerbil group fed $20 \mu \mathrm{g} \beta$-cryptoxanthin/d; CX40, gerbil group fed $40 \mu \mathrm{g} \beta$-cryptoxanthin/d; CX60, gerbil group fed $60 \mu \mathrm{g}$ $\beta$-cryptoxanthin/d.

* Corresponding author: B. J. Burri, fax +1 530752 4390, email betty.burri@ars.usda.gov 
Table 1. Initial and final gerbil group weights $\dagger$

(Mean values with their standard errors, $n 5$ (baseline) or $n 8$ (treatment groups))

\begin{tabular}{llllll}
\hline & \multicolumn{2}{c}{ Arrival } & & \multicolumn{2}{c}{ End } \\
\cline { 2 - 3 } \cline { 5 - 6 } & \multicolumn{2}{c}{ Weight $(\mathrm{g})$} & & \multicolumn{2}{c}{ Weight $(\mathrm{g})$} \\
\cline { 2 - 3 } & Mean & SEM & & Mean & SEM \\
\hline Baseline & 40.9 & 1.2 & & 42.3 & 2.34 \\
CX20 & 39.1 & 0.6 & & $51 \cdot 7^{*}$ & 0.96 \\
CX40 & 39.5 & 0.8 & & $50 \cdot 1^{*}$ & 1.15 \\
CX60 & 40.0 & 0.5 & & $49.6^{*}$ & 0.80
\end{tabular}

CX20, gerbil group fed $20 \mu \mathrm{g} \beta$-cryptoxanthin/d; CX40, group fed $40 \mu \mathrm{g}$ $\beta$-cryptoxanthin/d; CX60, group fed $60 \mu \mathrm{g} \beta$-cryptoxanthin/d.

* Mean values were significantly different from those of the baseline group $(P<0.05)$.

$\dagger$ Gerbils began the depletion diet when $51 \mathrm{~d}$ old. The baseline group was euthanised at $55 d$ and the experimental groups at $75 d$.

The purpose of the present study was to gain insight into the whole-body tissue distribution and response to different levels of $\beta$-cryptoxanthin consumption in the gerbil. The objectives of the study were to test fourteen tissues and blood from Mongolian gerbils fed three different concentrations of $\beta$-cryptoxanthin, to identify locations of interest, and the effect of these dosages on the distribution of $\beta$-cryptoxanthin in tissues.

\section{Materials and methods \\ Chemicals and reagents}

All-trans-retinol, all-trans-retinyl palmitate, all-trans- $\beta$ carotene, all-trans-retinal, $\beta$-ionone, pyrogallate and anhydrous sodium borohydride were purchased from SigmaAldrich Company. All-trans- $\beta$-cryptoxanthin and lycopene were purchased from Chromadex, and all-trans- $\alpha$-carotene, all-trans-lutein and all-trans-3,4-didehydroretinol were purchased from Santa Cruz Biochemicals. 3-Hydroxyretinal was purchased from Toronto Research Chemicals, and $\beta$-apo-10-carotenal was purchased from Carotenature. Hexane was purchased from Burdick and Jackson Laboratories, Inc. All other chemicals were purchased from Thermo Fisher Scientific. All solvents were of HPLC grade.

Both retinal-O-ethyloxime and 3-hydroxyretinol standards were not commercially available for purchase and required synthesis. Retinal-O-ethyloxime was synthesised as described previously $^{(21)}$. 3-Hydroxyretinol was synthesised from 3-hydroxyretinal. Briefly, $1 \mathrm{mg}$ of 3-hydroxyretinal in ethanol was reduced to 3-hydroxyretinol by the addition of $12 \mathrm{mg}$ sodium borohydride. Conversion appeared to be complete (100\%), with purity confirmed by proton NMR spectrometry and HPLC.

\section{Animals}

Female Mongolian gerbils (Meriones unguiculatus, $n$ 29), age $34 \mathrm{~d}$, were purchased from Charles River Laboratories. Upon arrival, gerbils were housed in individual plastic cages in a temperature-controlled room $\left(25^{\circ} \mathrm{C}\right)$ with a diurnal cycle of
$12 \mathrm{~h}$ light-12 h dark. Gerbils were weighed daily. After the acclimatisation period, gerbils were fed a vitamin A-deficient diet. After $5 \mathrm{~d}$, five gerbils with extreme weights were euthanised for baseline test measurements. Gerbils were euthanised by being placed in a $\mathrm{CO}_{2}$ chamber, followed by exsanguination. The remaining gerbils were separated into three weight-matched groups (eight gerbils per group; Table 1). Gerbils ate the same diet throughout the study, supplemented with one of three $\beta$-cryptoxanthin treatments. During the $21 \mathrm{~d}$ treatment period, gerbils were weighed every 2nd day. During the last $2 \mathrm{~d}$ of the experiment, two gerbils from each group were transferred into individual metabolism cages, and urine and faecal samples were collected every $6 \mathrm{~h}$.

After 3 weeks of treatment, gerbils were euthanised, as described previously, $20-24 \mathrm{~h}$ after their last treatment dose in order to allow for complete absorption and circulation of $\beta$-cryptoxanthin in the body. Blood was collected via cardiac puncture, and tissue samples were dissected immediately and stored at $-70^{\circ} \mathrm{C}$ until retinoid and carotenoid analysis. All animal handling procedures were approved by the University of California, Davis Institutional Animal Care and Use Committee (approval 13104).

\section{Diets}

Before the study, while at Charles River Laboratories, gerbils consumed the Purina 5L2F 18\% Rodent-Kingston diet (Purina). Upon arrival at the Western Human Nutrition Research Center, the gerbils began a $17 \mathrm{~d}$ acclimatisation period during which they consumed the Purina 5001 Laboratory Rodent Diet (Purina) ad libitum. Once the study began, the gerbils consumed a diet void of vitamin A and provitamin A carotenoids (Harlan Teklad TD.09084 Gerbil Vitamin A Deficient Diet; Harlan Teklad; Table 2) and water ad libitum.

All gerbils were fed a $246 \mu$ l dose of tangerine concentrate (kindly donated by Ventura Coastal; lot no. VP71155) containing $20 \mu \mathrm{g} / \mathrm{d}$ of $\beta$-cryptoxanthin and smaller amounts $(<1 \mu \mathrm{g} / \mathrm{d})$ of

Table 2. Proximate composition of the vitamin A-deficient diet* fed to gerbils during the study

\begin{tabular}{lc}
\hline & $\mathrm{g} / \mathrm{kg}$ \\
\hline Vitamin-free casein & 200 \\
DL-Met & 3 \\
Sucrose & $436 \cdot 3$ \\
Maize starch & $201 \cdot 4$ \\
Cottonseed oil & 201 \\
Cellulose & 30 \\
Mineral mix (AIN-93G-MX) & 35 \\
Calcium carbonate & 4 \\
Magnesium oxide & $1 \cdot 7$ \\
Vitamin mix, without choline, vitamins A, D and E† & 5 \\
Choline dihydrogen citrate & 3.5 \\
Vitamin D, cholecalciferol & $0 \cdot 004$ \\
Vitamin E, DL- $\alpha$-tocopheryl acetate & $0 \cdot 12$ \\
\hline
\end{tabular}

AIN, American Institute of Nutrition.

* Harlan Teklad TD.09084 Gerbil Vitamin A Deficient Diet.

† Vitamin mix provided (mg/kg feed): biotin, 0.4; calcium pantothenate, $66 \cdot 1$; folic acid, 2; inositol, 110.1; menadione, 49.6; niacin, 99.1; p-aminobenzoic acid 110.1; pyrodoxine- $\mathrm{HCl}$, 22; riboflavin, 22; thiamin- $\mathrm{HCl}$, 22; vitamin $\mathrm{B}_{12}, 29.7$; ascorbic acid $(97 \cdot 5 \%), 1016 \cdot 6$. 
other provitamin A carotenoids. The concentrate was made from washed, sanitised and pasteurised tangerine juice with most pulp removed and oils extracted. BRIX was 64.97 (w/w), pH $4 \cdot 88, \%$ oil 0 and RGB angle hue (colour) $41 \cdot 4$.

It was fed with $20 \mu \mathrm{l}$ of extra-virgin olive oil (Tantillo; T.M. Imports) using a Gilson positive-displacement pipette (Rainin Instruments). In addition, two treatment groups (CX40 and CX60) also consumed 20 and $40 \mu \mathrm{g} / \mathrm{d}$, respectively, of $\beta$-cryptoxanthin standard (Chromadex) fed directly via the displacement pipette.

\section{Carotenoid and vitamin A composition of the diet}

Carotenoids were extracted from the tangerine concentrate using methods modified from Breithaupt et al. ${ }^{(22)}$ and Rodriguez-Amaya and Kimura ${ }^{(23)}$.

HPLC analysis of the tangerine concentrate was performed on an Agilent 1100 system (Agilent Technologies) using a gradient method ${ }^{(24)}$. Carotenoids were separated using a YMC C30, $5 \mu \mathrm{m}, 4.6 \times 250 \mathrm{~mm}$ reverse-phase column (Waters Corporation).

arotenoids and retinoids in the feed were extracted using a method similar to that of Howe et $a l .{ }^{(25)}$. Carotenoids in the gerbil feed, blood and tissues were measured by a reversephase isocratic method ${ }^{(26)}$ on an Agilent 1100 system (Agilent Technologies). Carotenoids and retinoids were separated using a $3 \times 125 \mathrm{~mm}, 3 \mu \mathrm{m}$, Waters Spherisorb ODS2 column (Waters Corporation).

Most retinoids were analysed at $325 \mathrm{~nm}$ and carotenoids at $452 \mathrm{~nm}$. The internal standard retinal-O-ethyloxime (added for quality control) and 3,4-didehydroretinol were analysed at $357 \mathrm{~nm}$. Carotenoid standards were prepared in hexanemethylene chloride (4:1), while retinol and retinal-Oethyloxime were prepared in methanol and retinyl palmitate in hexane. Standard concentrations were verified on a spectrophotometer (Spectronic Genesys 5; Milton Roy Company). On each test day, inter-assay precision was evaluated using a pooled plasma sample purchased from UTAK. The inter-assay precision was $4.5 \%$ for retinol and $5.9 \%$ for $\beta$-cryptoxanthin.

The purity of the $\beta$-cryptoxanthin standards fed to the gerbils was monitored by HPLC and determined to be $>99 \%$ all-trans- $\beta$-cryptoxanthin. Concentrations were verified using a spectrophotometer.

\section{Experimental design}

After acclimatisation, gerbils were randomly assigned to one of three treatment groups receiving 20,40 or $60 \mu \mathrm{g} \beta$-cryptoxanthin/ d (CX20, CX40 and CX60, respectively; Table 3). All gerbils received $246 \mu \mathrm{l}$ tangerine concentrate containing $20 \mu \mathrm{g} \beta$-cryptoxanthin/ $\mathrm{d}$ and small amounts of $\beta$ - and $\alpha$-carotenes $(<1 \mu \mathrm{g} / \mathrm{d})$. To test the effects of higher $\beta$-cryptoxanthin concentrations, we added pure $\beta$-cryptoxanthin to the juice. Gerbils in groups CX40 and CX60 received an additional 20 or $40 \mu \mathrm{g} \beta$-cryptoxanthin/d dissolved in ethanol, respectively, for $21 \mathrm{~d}$. We collected samples from fourteen tissues and blood.

\section{Blood and tissue extraction and analysis}

Since systematic quantification errors are often found when using varying volumes of blood ${ }^{(27)}$, retinoids and carotenoids were extracted from a standardised volume of $400 \mu \mathrm{l}$ whole blood. Methanol ( $1 \mathrm{ml})$ with 3\% pyrogallate and the internal standard retinal-O-ethyloxime as a control for recovery was added to the whole blood and vortexed for $30 \mathrm{~s}$. Thereafter, $300 \mu \mathrm{l}$ deionised water and $2 \mathrm{ml}$ hexane were added, and the mixture was vortexed for an additional $1 \mathrm{~min}$ before being centrifuged for $5 \mathrm{~min}$ at $2500 \mathrm{rpm}$ at $4^{\circ} \mathrm{C}$. The hexane layer was collected, and the extraction procedure repeated. The sample was reconstituted in a $100 \mu \mathrm{l}$ mobile phase. Blood was analysed in duplicate. Blood was not saponified since no esters were detected.

All tissues were extracted using a different procedure. Precautions were taken to obtain the most possible representative tissue samples by removing blemishes from large organs. Since

Table 3. Composition of vitamin A and carotenoids from the pre-study and experimental diets*

(Mean values with their standard errors, $n 3$ (pre-study diets) or $n 6$ (experimental diet))

\begin{tabular}{|c|c|c|c|c|c|c|c|c|c|c|}
\hline & \multirow{2}{*}{\multicolumn{2}{|c|}{$\frac{\text { Charles River† }}{\text { All groups }(\mu \mathrm{g} / \mathrm{g})}$}} & \multirow{2}{*}{\multicolumn{2}{|c|}{$\begin{array}{c}\text { UCD acclimatisation } \ddagger \\
\text { All groups }(\mu \mathrm{g} / \mathrm{g})\end{array}$}} & \multicolumn{6}{|c|}{ Experimental§ $\|$ ฯ } \\
\hline & & & & & \multicolumn{2}{|c|}{ CX20 $(\mu \mathrm{g} / \mathrm{g})$} & \multicolumn{2}{|c|}{ CX40 $(\mu \mathrm{g} / \mathrm{g})$} & \multicolumn{2}{|c|}{ CX60 $(\mu \mathrm{g} / \mathrm{g})$} \\
\hline & Mean & SEM & Mean & SEM & Mean & SEM & Mean & SEM & Mean & SEM \\
\hline Vitamin A & $16 \cdot 30$ & 4.08 & 11.80 & 3.47 & \multicolumn{2}{|c|}{ ND } & \multicolumn{2}{|c|}{ ND } & \multicolumn{2}{|c|}{ ND } \\
\hline$\beta$-Cryptoxanthin & \multicolumn{2}{|c|}{ ND } & \multicolumn{2}{|c|}{ ND } & $3 \cdot 11$ & 0.10 & $6 \cdot 20$ & 0.20 & $9 \cdot 30$ & 0.30 \\
\hline$\beta$-Carotene & 0.59 & 0.01 & 0.79 & 0.01 & 0.13 & 0.02 & $0 \cdot 13$ & 0.02 & 0.13 & 0.02 \\
\hline$\alpha$-Carotene & 0.07 & 0.01 & 0.08 & 0.01 & 0.02 & 0.01 & 0.02 & 0.01 & 0.02 & 0.01 \\
\hline Lutein & \multicolumn{2}{|c|}{ ND } & \multicolumn{2}{|c|}{ ND } & 0.20 & 0.02 & \multirow{2}{*}{\multicolumn{2}{|c|}{ ND }} & 0.20 & 0.02 \\
\hline Lycopene & & & & & & & & & \multicolumn{2}{|c|}{ ND } \\
\hline
\end{tabular}

UCD, University of California, Davis; CX20, gerbil group fed $20 \mu \mathrm{g} \beta$-cryptoxanthin/d; CX40, gerbil group fed $40 \mu \mathrm{g} \beta$-cryptoxanthin/d; CX60, gerbil group fed $60 \mu \mathrm{g} \beta$-cryptoxanthin/d; ND, not detected.

${ }^{*} \beta$-Cryptoxanthin standard concentrations were monitored throughout the study.

†Purina 5L2F 18\% Rodent-Kingston diet. Gerbils consumed this diet at Charles River Laboratories, before their arrival (34 d).

$\ddagger$ Purina 5001 Laboratory Rodent diet. Gerbils consumed this diet during a $17 \mathrm{~d}$ acclimatisation period.

$\S$ Calculation of $\mu \mathrm{g} / \mathrm{g}$ for the experimental diets based on the combined consumption of tangerine concentrate and oil, and the National Research Council estimation of $6 \mathrm{~g}$ feed consumed per $\mathrm{d}$.

|| Experimental diet consisted of $246 \mu$ l tangerine concentrate and $20 \mu \mathrm{l}$ oil, plus a Harlan Teklad TD.09084 Vitamin A Deficient Gerbil Diet for all the groups.

I In addition to the experimental diet, groups CX40 and CX60 received 20 and $40 \mu \mathrm{g} \beta$-cryptoxanthin standard, respectively. 
most organs were small and we expected low $\beta$-cryptoxanthin concentrations in many of them, the entire organs were extracted and single $70 \mu$ injections were performed. The exceptions were liver, adipose and the small and large intestine, where portions of organs were dissected from the same regions of these organs. For the liver, portions of the upper and lower liver were dissected and mixed, and duplicate injections of $5 \mu \mathrm{l}$ were performed. A representative portion of the abdominal adipose was dissected and extracted as a whole. For the small and large intestine, each had portions from both ends and the middle that were collected for extraction.

The range of tissue sample weights was as follows: liver, 0.060-0.092 g; abdominal adipose, 0.017-0.29 g; small intestine, $0.27-0.96 \mathrm{~g}$; large intestine, $0 \cdot 19-0.46 \mathrm{~g}$. Whole-organ weights were as follows: kidneys, $0 \cdot 17-0.33 \mathrm{~g}$; adrenals, 0.013-0.055 g; pancreas, $0.032-0.21 \mathrm{~g}$; heart, $0.18-0.31 \mathrm{~g}$; lungs, $0 \cdot 17-0 \cdot 41 \mathrm{~g}$; spleen, $0 \cdot 033-0 \cdot 10 \mathrm{~g}$; eyes, $0 \cdot 16-0 \cdot 24 \mathrm{~g}$; brain, $0.35-0.94 \mathrm{~g}$; stomach, 0.094-0.48 g; caecum, $0 \cdot 14-0 \cdot 32 \mathrm{~g}$. There were no significant differences in tissue weights between the groups.

Tissue samples were extracted using a different procedure from that used for blood. Tissues were saponified to reduce retinyl esters. Samples were ground with anhydrous sodium sulphate $(0 \cdot 2-1 \mathrm{~g})$, mixed with $1-1.5 \mathrm{ml}$ methanol containing $2 \%$ pyrogallate and the internal standard retinal-O-ethyloxime, and vortexed for $30 \mathrm{~s}$. (The amount of anhydrous sodium sulphate and solvents used were adjusted based on the sample size.) Subsequently, samples were saponified with an equal volume of potassium hydroxide (20\% in water) and vortexed for $5 \mathrm{~min}$ before being placed in a shaking water-bath $\left(37^{\circ} \mathrm{C}\right)$ for $1 \mathrm{~h}$. This led to the conversion of most of the retinyl esters to retinol, simplifying our chromatograms to allow for the detection of other $\beta$-cryptoxanthin metabolites. Henceforth, we use the term 'vitamin A' to refer to the retinol and retinyl ester residues left after saponification. Less than $2 \cdot 5 \%$ of the saponified vitamin A remained in the form of retinyl esters. Then, 200-400 $\mu \mathrm{l}$ DI water and $3 \mathrm{ml}$ hexane were added, and the mixture was vortexed for an additional $2 \mathrm{~min}$ before being centrifuged for $5 \mathrm{~min}$ at $2500 \mathrm{rpm}$ and $4^{\circ} \mathrm{C}$. The hexane layer was extracted twice and filtered through a $0 \cdot 2 \mu \mathrm{m}$ Acrodisc filter into a separate test-tube under $\mathrm{N}_{2}$ gas. The sample was dried completely, reconstituted in the mobile phase and analysed as described previously.

A gradient HPLC method was performed on an Agilent 1200 system (Agilent Technologies) to test for the presence of $\beta$-cryptoxanthin apocarotenoids including $\beta$-apo-10-carotenal and 3-hydroxy- $\beta$-apo-10-carotenal in liver tissue. Briefly, representative samples from each gerbil liver were combined to form a $1 \mathrm{~g}$ sample of liver for each test group. This sample was extracted using the procedure for tissue extraction described above. Compounds were separated using a Restek Viva reverse-phase column (C18, $5 \mu \mathrm{m}, 5 \times 250 \mathrm{~mm}$; Restek) at room temperature by a previously described method ${ }^{(28)}$.

A gradient HPLC method was performed on an Agilent 1100 system (Agilent Technologies) to test for the presence of other potential $\beta$-cryptoxanthin metabolites (3-hydroxyretinol and 3,4-didehydroretinol) in liver tissue. Briefly, a $0 \cdot 2 \mathrm{~g}$ sample of liver from each group was extracted using the procedure for tissue extraction, as described previously. Compounds were separated using a YMC C30, S-5, $4.6 \times 250 \mathrm{~mm}$ column (Waters Corporation), as described previously ${ }^{(29)}$.

\section{Statistical analyses}

To approximate the total amount of $\beta$-cryptoxanthin and vitamin A in gerbil blood, the weight $(\mathrm{g})$ of each gerbil was multiplied by the blood volume approximation $(72 \mathrm{ml} / \mathrm{kg})$, estimated from a healthy gerbil sample by the Iowa State University Institutional Animal Care and Use Committee (IACUC) $^{(30)}$. An estimate was not available for the total weight

Table 4. Weight of gerbil organs $(\mathrm{g})$

(Mean values with their standard errors, $n 5$ (baseline) or $n 8$ (treatment groups))

\begin{tabular}{|c|c|c|c|c|c|c|c|c|}
\hline & \multicolumn{2}{|c|}{ Baseline } & \multicolumn{2}{|c|}{ CX20 } & \multicolumn{2}{|c|}{ CX40 } & \multicolumn{2}{|c|}{ CX60 } \\
\hline & Mean & SEM & Mean & SEM & Mean & SEM & Mean & SEM \\
\hline Adipose† & 5.49 & 0.30 & $6 \cdot 71^{*}$ & 0.12 & $6 \cdot 50^{*}$ & 0.15 & $6 \cdot 44^{*}$ & 0.10 \\
\hline Blood $\ddagger$ & \multicolumn{2}{|c|}{ NT } & 3.72 & 0.07 & 3.60 & 0.08 & 3.57 & 0.06 \\
\hline Liver & 1.87 & 0.22 & $2 \cdot 05$ & 0.06 & $2 \cdot 08$ & 0.12 & $2 \cdot 30$ & 0.19 \\
\hline Brain & 0.81 & 0.05 & $0 \cdot 81$ & 0.02 & 0.82 & 0.03 & 0.73 & 0.06 \\
\hline Small intestine & 0.67 & 0.09 & 0.75 & 0.08 & 0.74 & 0.01 & 0.63 & 0.07 \\
\hline Kidneys & 0.45 & 0.03 & 0.50 & 0.02 & 0.52 & 0.02 & 0.57 & 0.02 \\
\hline Large intestine & 0.60 & 0.10 & 0.52 & 0.08 & 0.44 & 0.06 & 0.41 & 0.03 \\
\hline Stomach & 0.24 & 0.04 & 0.31 & 0.04 & 0.32 & 0.03 & 0.30 & 0.03 \\
\hline Lungs & 0.28 & 0.01 & 0.33 & 0.02 & 0.28 & 0.02 & 0.29 & 0.02 \\
\hline Caecum & \multicolumn{2}{|c|}{ NT } & 0.23 & 0.01 & 0.21 & 0.02 & $0 \cdot 26$ & 0.02 \\
\hline Eyes & 0.20 & 0.01 & 0.22 & 0.01 & 0.21 & 0.01 & 0.21 & 0.01 \\
\hline Heart & 0.22 & 0.01 & 0.25 & 0.01 & 0.23 & 0.01 & $0 \cdot 24$ & 0.01 \\
\hline Pancreas & 0.14 & 0.01 & 0.18 & 0.01 & 0.16 & 0.01 & 0.14 & 0.02 \\
\hline Spleen & \multicolumn{2}{|c|}{ NT } & 0.05 & 0.01 & 0.05 & 0.01 & 0.05 & 0.01 \\
\hline Adrenal glands & 0.03 & 0.01 & 0.03 & 0.01 & 0.03 & 0.01 & 0.03 & 0.01 \\
\hline
\end{tabular}

CX20, gerbil group fed $20 \mu \mathrm{g} \beta$-cryptoxanthin/d; CX40, gerbil group fed $40 \mu \mathrm{g} \beta$-cryptoxanthin/d; CX60, gerbil group fed $60 \mu \mathrm{g} \beta$-cryptoxanthin/d; NT, not tested.

* Mean value was significantly different from that at baseline $(P<0.05)$.

$\dagger$ Adipose calculation is based on the data showing $12.9 \%$ total body fat in similar gerbils ${ }^{(31)}$.

$\ddagger$ Blood volume estimate based on the lowa State University Institutional Animal Care and Use Committee (IACUC) calculation ${ }^{(30)}$. 
of adipose tissue from this reference, so we used the data from a study that tested normal-weight, similarly aged, female gerbils consuming a regular diet as a reference for the gerbil groups ${ }^{(31)}$.

Outcome variables were assessed for conformity to a normal distribution by the Shapiro-Wilk test and transformed, if necessary, using log or reciprocal values. If a suitable transformation could not be found, analyses were performed on the ranks of the variables using the Kruskal-Wallis test or Spearman's rank correlation coefficient.

Tissue concentrations were compared using both nmol/g and nmol/organ. Differences in $\beta$-cryptoxanthin concentrations, vitamin A concentrations, and gerbil and organ weights were compared between groups using ANOVA, followed by Tukey's test for pairwise comparisons. Pearson's or Spearman's correlations were calculated to determine the associations between tissues, compounds and the $\beta$-cryptoxanthin dose.

A post hoc analysis was performed to further investigate trends in the tissue distribution of $\beta$-cryptoxanthin and vitamin A. The preferential accumulation of both the compounds in specific tissues was assessed using Pearson's or Spearman's rank correlation tests.

Vitamin A (retinol and retinyl ester residues) was present in all tissues at baseline, and thus the baseline group was included in ANOVA for vitamin A concentrations. The exceptions were the blood, spleen and caecum whose baseline group tissues were not collected. Values are presented as means with their standard errors. $P$ values $<0.05$ were considered as statistically significant for testing the effects of concentration. However, when comparisons between tissues were made, we used a significance level of 0.01 because of the large number of correlations made. Statistical analyses were performed using Statistical Analysis Systems statistical software (Windows version 9.3; SAS Institute, Inc.).

\section{Results}

\section{Body weight}

Gerbil weights at the beginning and end of the experiment are shown in Table 1. The weight gain of the treatment groups

Table 5. Total and per $g$ weight concentrations of $\beta$-cryptoxanthin in the plasma and tissue of gerbils at baseline or fed 20,40 or $60 \mu \mathrm{g} \beta$-cryptoxanthin

(Mean values with their standard errors, $n 5$ (baseline and all caecal samples) or $n 8$ (treatment groups))

\begin{tabular}{|c|c|c|c|c|c|c|c|}
\hline & \multirow[b]{2}{*}{ Baseline $^{*}$} & \multicolumn{2}{|c|}{ CX20 } & \multicolumn{2}{|c|}{ CX40 } & \multicolumn{2}{|c|}{ CX60 } \\
\hline & & Mean & SEM & Mean & SEM & Mean & SEM \\
\hline \multicolumn{8}{|c|}{$\beta$-Cryptoxanthin (nmol/organ) } \\
\hline Liver & ND & $13 \cdot 3^{\mathrm{a}}$ & 0.44 & $16 \cdot 2^{b}$ & 0.91 & $17 \cdot 8^{b}$ & 0.71 \\
\hline Adipose & ND & $7 \cdot 78$ & 1.60 & 9.73 & 0.38 & 9.99 & 1.55 \\
\hline Blood & NT & $1 \cdot 19$ & 0.06 & 1.05 & 0.09 & 1.07 & 0.14 \\
\hline Caecum & NT & 0.05 & 0.01 & 0.05 & 0.01 & 0.10 & 0.01 \\
\hline Kidneys & ND & $0.01^{\mathrm{a}}$ & 0.01 & $0.06^{\mathrm{b}}$ & 0.01 & $0.06^{b}$ & 0.01 \\
\hline Small intestine & ND & $0.03^{a}$ & 0.01 & $0.04^{a}$ & 0.01 & $0.06^{b}$ & 0.01 \\
\hline Stomach & ND & 0.04 & 0.01 & 0.06 & 0.01 & 0.05 & 0.01 \\
\hline Large intestine & ND & $0.03^{a}$ & 0.01 & $0.03^{a}$ & 0.01 & $0.05^{b}$ & 0.01 \\
\hline Lungs & ND & 0.01 & 0.01 & 0.01 & 0.01 & 0.05 & 0.01 \\
\hline Spleen & NT & $0.02^{\mathrm{a}}$ & 0.01 & $0.03^{\mathrm{b}}$ & 0.01 & $0.04^{\mathrm{b}}$ & 0.01 \\
\hline Heart & ND & 0.03 & 0.01 & 0.04 & 0.01 & 0.03 & 0.01 \\
\hline Adrenal glands & ND & 0.03 & 0.01 & 0.03 & 0.01 & 0.03 & 0.01 \\
\hline Pancreas & ND & \multicolumn{2}{|c|}{ ND } & \multicolumn{2}{|c|}{ ND } & $0.02 \dagger$ & 0.01 \\
\hline Brain & ND & \multicolumn{2}{|c|}{ ND } & \multicolumn{2}{|c|}{ ND } & \multicolumn{2}{|c|}{ ND } \\
\hline Eyes & ND & \multicolumn{2}{|c|}{ ND } & \multicolumn{2}{|c|}{ ND } & \multicolumn{2}{|c|}{ ND } \\
\hline \multicolumn{8}{|c|}{$\beta$-Cryptoxanthin (nmol/g) } \\
\hline Liver & ND & $6 \cdot 50^{a}$ & 0.19 & $7 \cdot 83^{b}$ & 0.33 & $7 \cdot 89^{b}$ & 0.26 \\
\hline Adipose & ND & 1.17 & 0.24 & 1.50 & 0.04 & 1.54 & 0.24 \\
\hline Adrenal glands & ND & 0.96 & 0.05 & 1.00 & $0 \cdot 10$ & 0.94 & $0 \cdot 10$ \\
\hline Spleen & NT & 0.42 & 0.03 & 0.50 & 0.03 & 0.85 & 0.04 \\
\hline Caecum & NT & 0.20 & 0.02 & 0.22 & 0.04 & 0.37 & 0.13 \\
\hline Blood & NT & 0.32 & 0.02 & \multirow{2}{*}{\multicolumn{2}{|c|}{$\begin{array}{ll}0.29 & \mathrm{ND}\end{array}$}} & 0.30 & 0.04 \\
\hline Pancreas & ND & \multicolumn{2}{|c|}{ ND } & & & 0.23 & $0.11 \dagger$ \\
\hline Stomach & ND & $0.12^{a}$ & 0.01 & $0.19^{b}$ & 0.02 & $0 \cdot 18^{a, b}$ & 0.03 \\
\hline Heart & ND & $0 \cdot 10^{\mathrm{a}}$ & 0.03 & $0 \cdot 17^{\mathrm{b}}$ & 0.01 & $0 \cdot 14^{a, b}$ & 0.01 \\
\hline Large intestine & ND & $0.07^{a}$ & 0.02 & $0.08^{a, b}$ & 0.01 & $0 \cdot 13^{\mathrm{b}}$ & 0.03 \\
\hline Kidneys & ND & $0.03^{\mathrm{a}}$ & 0.01 & $0 \cdot 11^{\mathrm{b}}$ & 0.01 & $0 \cdot 10^{\mathrm{b}}$ & 0.01 \\
\hline Small intestine & ND & $0.05^{\mathrm{a}}$ & 0.01 & $0.05^{\mathrm{b}}$ & 0.01 & $0.09^{c}$ & 0.01 \\
\hline Lungs & ND & 0.02 & 0.01 & 0.02 & 0.01 & 0.02 & 0.01 \\
\hline Brain & ND & \multicolumn{2}{|c|}{ ND } & \multicolumn{2}{|c|}{ ND } & \multicolumn{2}{|c|}{ ND } \\
\hline Eyes & ND & \multicolumn{2}{|c|}{ ND } & \multicolumn{2}{|c|}{ ND } & \multicolumn{2}{|c|}{ ND } \\
\hline
\end{tabular}

CX20, gerbil group fed $20 \mu \mathrm{g} \beta$-cryptoxanthin/d; CX40, gerbil group fed $40 \mu \mathrm{g} \beta$-cryptoxanthin/d; CX60, gerbil group fed $60 \mu \mathrm{g}$ $\beta$-cryptoxanthin/d; ND, not detected; NT, not tested.

${ }^{a, b, c}$ Mean values with unlike superscript letters were significantly different $(P<0.05)$.

${ }^{*}$ All baseline group tissues measured were significantly different from the treatment groups $(P<0.05)$.

† Group CX60 was significantly different from all the other groups. 
CX20, CX40 and CX60 after $21 \mathrm{~d}$ was 7·1 (SEM 1·3), $5 \cdot 7$ (SEM 1.3) and $5.2(\operatorname{sem} 0 \cdot 8) \mathrm{g}$, respectively. The three treatment groups were not significantly different from each other.

\section{Feed contents}

Both the pre-study diet consumed by gerbils while at Charles River Laboratories and the diet consumed during the acclimatisation period contained high concentrations of vitamin $\mathrm{A}$, in the form of retinyl acetate, and minimal amounts of carotenoids (Table 3). We measured the retinoid and carotenoid content of the diet consumed while at Charles River Laboratories, as well as the acclimatisation diet consumed when the gerbils arrived at our facility. It should be noted that we tested a small sample of the diet fed to the gerbils. Purina specification stated that the Charles River and acclimatisation diets contained $13.2 \mu \mathrm{g}$ vitamin $\mathrm{A} / \mathrm{g}$ and $4.5 \mu \mathrm{g} / \mathrm{g}$, respectively. The vitamin A-deficient diet was confirmed to contain undetectable retinoid or carotenoid concentrations. Thus, the sole source of carotenoids in the vitamin A-deficient diet was the $246 \mu \mathrm{l}$ dose of tangerine concentrate and $\beta$-cryptoxanthin supplements provided. Specifically, the tangerine concentrate contained
$81 \cdot 3(\operatorname{sem} 2 \cdot 6) \mu \mathrm{g} / \mathrm{g}$ of $\beta$-cryptoxanthin, 3.5 (SEM $0 \cdot 4$ ) $\mu \mathrm{g} / \mathrm{g}$ of $\beta$-carotene, 0.5 (SEM 0.04$) \mu \mathrm{g} / \mathrm{g}$ of $\alpha$-carotene and 6.0 (SEM 0.5$) \mu \mathrm{g} / \mathrm{g}$ of lutein. Thus, $\beta$-cryptoxanthin represented $>95 \%$ of the provitamin A carotenoid concentrations in the tangerine concentrate.

\section{$\beta$-Cryptoxanthin and vitamin A tissue concentrations}

The study measured $\beta$-cryptoxanthin concentrations in fourteen tissues and blood. Organ weights did not differ with treatment. The baseline group had a lower adipose weight because they were euthanised at a younger age and were smaller (Tables 1 and 4). Not surprisingly, statistical analyses using both $\mathrm{nmol} /$ organ and $\mathrm{nmol} / \mathrm{g}$ showed similar statistical differences (Tables 5 and 6).

$\beta$-Cryptoxanthin was not present in any of the baseline tissues tested. After the treatment, $\beta$-cryptoxanthin increased in all the groups; however, there were significant differences between the groups in $\beta$-cryptoxanthin concentrations per organ (nmol $\beta$-cryptoxanthin/organ) and per $g$ observed in the liver, kidneys, pancreas, spleen, small intestine and large intestine (Tables 5 and 6).

Table 6. Total and per $\mathrm{g}$ weight concentrations of vitamin A in the plasma and tissue of gerbils at baseline or fed 20,40 or $60 \mu \mathrm{g} \beta$-cryptoxanthin (Mean values with their standard errors, $n 5$ (baseline and all caecal samples) or $n 8$ (treatment groups))

\begin{tabular}{|c|c|c|c|c|c|c|c|c|}
\hline & \multicolumn{2}{|c|}{ Baseline } & \multicolumn{2}{|c|}{ CX20 } & \multicolumn{2}{|c|}{ CX40 } & \multicolumn{2}{|c|}{ CX60 } \\
\hline & Mean & SEM & Mean & SEM & Mean & SEM & Mean & SEM \\
\hline \multicolumn{9}{|c|}{ Vitamin A (nmol/organ) } \\
\hline Liver & $2477 \cdot 0$ & $73 \cdot 6$ & $2253 \cdot 0$ & $82 \cdot 0$ & $2474 \cdot 0$ & $153 \cdot 1$ & $2460 \cdot 5$ & $267 \cdot 0$ \\
\hline Adipose & 53.9 & $19 \cdot 8$ & $114 \cdot 3$ & 38.4 & $97 \cdot 7$ & $19 \cdot 6$ & $102 \cdot 3$ & $20 \cdot 8$ \\
\hline Lungs & $78 \cdot 5^{\mathrm{a}}$ & $5 \cdot 3$ & $102 \cdot 7^{b}$ & 5.5 & $84 \cdot 8^{\mathrm{a}}$ & $6 \cdot 4$ & $95 \cdot 4^{\mathrm{a}}$ & $3 \cdot 1$ \\
\hline Eyes & $9 \cdot 94^{a}$ & 0.90 & $14 \cdot 2^{b}$ & 0.77 & $15 \cdot 2^{b}$ & 0.67 & $13 \cdot 9^{b}$ & 0.92 \\
\hline Blood & \multicolumn{2}{|c|}{ NT } & $7 \cdot 86$ & 0.83 & 7.02 & 0.68 & $6 \cdot 48$ & 0.72 \\
\hline Kidneys & $3 \cdot 20$ & 0.22 & $3 \cdot 81$ & 0.22 & 3.76 & 0.13 & $4 \cdot 15$ & 0.32 \\
\hline Spleen & \multicolumn{2}{|c|}{ NT } & $1 \cdot 21$ & 0.15 & 1.08 & 0.07 & 1.88 & 0.84 \\
\hline Small intestine & 0.98 & 0.13 & 0.69 & 0.04 & 0.68 & 0.02 & $1 \cdot 25$ & 0.45 \\
\hline Pancreas & $1 \cdot 44$ & 0.25 & 1.09 & 0.08 & $1 \cdot 37$ & 0.09 & 1.03 & 0.05 \\
\hline Brain & $1 \cdot 28$ & 0.15 & $1 \cdot 14$ & 0.07 & 1.04 & 0.12 & 1.03 & 0.20 \\
\hline Stomach & 0.76 & 0.07 & 0.83 & 0.05 & 0.80 & 0.07 & 0.87 & 0.10 \\
\hline Large intestine & $0 \cdot 75^{\mathrm{a}}$ & 0.16 & $0.36^{b}$ & 0.03 & $0.48^{a}$ & 0.04 & $0.87^{\mathrm{a}}$ & 0.28 \\
\hline Caecum & \multicolumn{2}{|c|}{ NT } & 0.44 & 0.05 & 0.45 & 0.06 & 0.67 & 0.08 \\
\hline Adrenal glands & 0.46 & 0.11 & 0.41 & 0.03 & 0.36 & 0.01 & 0.55 & 0.01 \\
\hline Heart & 0.41 & 0.17 & 0.31 & 0.03 & 0.24 & 0.04 & 0.46 & 0.15 \\
\hline \multicolumn{9}{|l|}{ Vitamin A (nmol/g) } \\
\hline Liver & $1405 \cdot 7$ & $187 \cdot 6$ & $1102 \cdot 4$ & 41.6 & $1225 \cdot 2$ & $116 \cdot 9$ & $1147 \cdot 3$ & $150 \cdot 7$ \\
\hline Lungs & $281 \cdot 0$ & 25.5 & 318.5 & $22 \cdot 7$ & $310 \cdot 6$ & $31 \cdot 2$ & 337.8 & 23.4 \\
\hline Eyes & $49 \cdot 8^{a}$ & $4 \cdot 00$ & $66 \cdot 1^{\mathrm{b}}$ & 4.45 & $71 \cdot 7^{\mathrm{b}}$ & 4.48 & $66 \cdot 5^{\mathrm{b}}$ & 3.80 \\
\hline Spleen & \multicolumn{2}{|c|}{$\mathrm{NT}^{*}$} & $23 \cdot 8$ & 3.01 & $20 \cdot 8$ & 2.54 & $28 \cdot 7$ & $7 \cdot 47$ \\
\hline Adipose & $12 \cdot 3$ & 2.9 & $16 \cdot 4$ & $5 \cdot 1$ & 14.9 & 2.73 & $15 \cdot 8$ & $3 \cdot 18$ \\
\hline Adrenal glands & $17 \cdot 4$ & $4 \cdot 17$ & $12 \cdot 3$ & 0.51 & $12 \cdot 8$ & 1.59 & $18 \cdot 4$ & 5.02 \\
\hline Pancreas & $10 \cdot 1$ & 1.95 & 6.49 & 0.68 & $8 \cdot 89$ & 0.91 & $10 \cdot 3$ & 3.59 \\
\hline Kidneys & $7 \cdot 33$ & 0.94 & 7.63 & 0.49 & $7 \cdot 29$ & 0.36 & $7 \cdot 35$ & 0.62 \\
\hline Stomach & 3.49 & 0.58 & $2 \cdot 87$ & 0.31 & 2.63 & 0.25 & 2.95 & 0.24 \\
\hline Caecum & \multicolumn{2}{|c|}{ NT } & 1.92 & 0.21 & $2 \cdot 19$ & 0.28 & $2 \cdot 61$ & 0.45 \\
\hline Large intestine & 1.69 & 0.56 & 1.06 & 0.41 & $1 \cdot 23$ & 0.21 & $2 \cdot 18$ & 0.63 \\
\hline Heart & $1 \cdot 87$ & 0.79 & $1 \cdot 26$ & 0.14 & 1.05 & 0.13 & 1.92 & 0.62 \\
\hline Small intestine & $1.66^{a}$ & 0.56 & $1.03^{b}$ & 0.41 & $0.92^{b}$ & 0.21 & $1.90^{\mathrm{a}}$ & 0.63 \\
\hline Blood & \multicolumn{2}{|c|}{ NT } & $2 \cdot 12$ & 0.22 & 1.95 & 0.19 & $1 \cdot 81$ & 0.19 \\
\hline Brain & 1.56 & 0.11 & 1.41 & 0.08 & $1 \cdot 27$ & 0.14 & 1.41 & 0.22 \\
\hline
\end{tabular}

CX20, gerbil group fed $20 \mu \mathrm{g} \beta$-cryptoxanthin/d; CX40, gerbil group fed $40 \mu \mathrm{g} \beta$-cryptoxanthin/d; CX60, gerbil group fed $60 \mu \mathrm{g} \beta$-cryptoxanthin/d; NT, not tested.

${ }^{\mathrm{a}, \mathrm{b}}$ Mean values with unlike superscript letters were significantly different $(P<0.05)$.

*Vitamin A concentration includes retinol and saponified retinyl ester residues. 
When we compared $\beta$-cryptoxanthin tissue concentrations with each other, correlations were observed between the liver and kidneys $(P<0.0001)$, the liver and large intestine $(P<0 \cdot 0001)$, the kidneys and spleen $(P=0.0058)$ and the kidneys and large intestine $(P=0 \cdot 0002)$.

$\beta$-Cryptoxanthin concentrations in many tissues increased with the increasing amounts of $\beta$-cryptoxanthin in the diet, including the liver $(P=0.0002)$, kidneys $(P<0.0001)$, pancreas $(P<0.0001)$, small intestine $(P=0.023)$ and large intestine ( $P=0.0003)$.

Most $\beta$-cryptoxanthin was present in the liver. Other important storage sites were adipose tissue and blood. However, it appears that $\beta$-cryptoxanthin may be highly concentrated in certain tissues, regardless of organ size. As shown in Table 5, there were accumulations in the adrenal glands and spleen.

The primary route of excretion was via the faeces, as is expected for carotenoids ${ }^{(32)}$. A small amount of $\beta$-cryptoxanthin was also excreted in the urine. There was a significant difference in faecal excretion between the group fed the greatest amount of $\beta$-cryptoxanthin and that fed the least $(P=0 \cdot 021$; Table 7). There were no significant differences between the groups for urine excretion.

There were significant differences between the groups for total vitamin A concentrations (nmol/organ) in the eyes, lungs and large intestine (Table 5). Correlations for total vitamin A concentrations in tissues were observed between the adrenal gland and large intestine $(P=0.0048)$, the heart and pancreas $(P=0.0006)$ and the caecum and kidneys $(P=0.002)$. As $\beta$-cryptoxanthin intake increased, a concomitant rise in vitamin A concentrations per organ was observed in the caecum $(P=0.032)$ and large intestine $(P=0.0014)$.

Overall, $92 \%$ of the vitamin A measured in the tissues that we sampled was stored in the liver. Vitamin A was concentrated in the other tissues such as the lungs and eyes, and, to a lesser extent, the adipose tissue and adrenal glands. There were no significant differences between the groups in terms of faecal and urine excretion of vitamin A (Table 7).

Correlation tests were performed to identify the tissues, in which both $\beta$-cryptoxanthin and vitamin A concentrations appeared to be preferentially accumulated. These tissues

Table 7. Faeces and urine excretion per $d$ from gerbils fed 20,40 or $60 \mu \mathrm{g} \beta$-cryptoxanthin

(Mean values with their standard errors, $n 8$ )

\begin{tabular}{|c|c|c|c|c|c|c|}
\hline & \multicolumn{2}{|c|}{ CX20 } & \multicolumn{2}{|c|}{ CX40 } & \multicolumn{2}{|c|}{ CX60 } \\
\hline & Mean & SEM & Mean & SEM & Mean & SEM \\
\hline \multicolumn{7}{|c|}{$\beta$-Cryptoxanthin (nmol) } \\
\hline Faeces & $2 \cdot 32^{\mathrm{a}}$ & 0.04 & $4.93^{\mathrm{a}}$ & 0.39 & $6 \cdot 28^{b}$ & 0.75 \\
\hline Urine & 0.04 & 0.01 & 0.03 & 0.01 & 0.03 & 0.01 \\
\hline Total excretion & $2 \cdot 37^{\mathrm{a}}$ & 0.03 & $4.96^{\mathrm{a}}$ & 0.38 & $6 \cdot 32^{b}$ & 0.75 \\
\hline \multicolumn{7}{|l|}{ Vitamin A (nmol) } \\
\hline Faeces & 5.09 & $2 \cdot 24$ & 3.71 & 0.97 & $6 \cdot 16$ & 0.48 \\
\hline Urine & 0.58 & 0.12 & 0.5 & 0.02 & 0.66 & 0.15 \\
\hline Total excretion & $5 \cdot 67$ & $2 \cdot 12$ & $4 \cdot 21$ & 0.99 & $6 \cdot 82$ & 0.33 \\
\hline
\end{tabular}

CX20, gerbil group fed $20 \mu \mathrm{g} \beta$-cryptoxanthin/d; CX40, gerbil group fed $40 \mu \mathrm{g}$ $\beta$-cryptoxanthin/d; CX60, gerbil group fed $60 \mu \mathrm{g} \beta$-cryptoxanthin/d.

a,b Mean values with unlike superscript letters were significantly different $(P<0.05)$. included the blood $(r \quad 0.61 ; P=0.0015)$, brain $(r \quad 0.68$; $P=0.0003)$, adipose $(P=0.022)$, caecum $(r 0.63 ; P=0.011)$, small intestine $(r 0.91 ; P<0.0001)$ and large intestine $(r 0.76$; $P<0.0001$ )

The gerbil liver was tested for the presence of several potential $\beta$-cryptoxanthin metabolites. Unfortunately, $\beta$-apo-10'-carotenal, $\beta$-ionone, 3,4-didehydroretinol and 3-hydroxyretinol were not detected. The limits of detection for $\beta$-apo-10'-carotenal, $\beta$-ionone, 3,4-didehydroretinol and 3-hydroxyretinol were $12.7,1.45,1.51$ and $5.07 \mathrm{nmol} / \mathrm{g}$ (or $4.78,0.28,0.43$ and $1.54 \mathrm{ng} / \mathrm{g}$ ), respectively.

\section{Discussion}

The present study is the first to investigate the tissue distribution and concentration response to $\beta$-cryptoxanthin intake in a recognised small animal model for human provitamin $\mathrm{A}$ carotenoid metabolism. Few studies have detected the presence of $\beta$-cryptoxanthin in tissues, and most of these have used an unsuitable animal model for human metabolism, such as gulls ${ }^{(17)}$, mice ${ }^{(16)}$ and rats ${ }^{(33)}$. However, studies using suitable animal models for human carotenoid metabolism, such as gerbils and ferrets, have detected $\beta$-cryptoxanthin in the lungs and liver ${ }^{(5,34)}$. Human studies have detected $\beta$-cryptoxanthin in the blood, brain and adipose tissue ${ }^{(35-38)}$.

As expected, we found $\beta$-cryptoxanthin concentrations in most tissues of all the treatment groups after feeding with tangerine concentrate. This appears to be the first report of $\beta$-cryptoxanthin in most tissues. However, we can compare the present results with those for other carotenoids, such as $\beta$-carotene. Liver and adipose tissue are known to be the two major storage sites of these other carotenoids ${ }^{(38,39)}$. Liver and adipose tissue were the main storage organs for all-trans- $\beta$-cryptoxanthin, accounting for $59 \cdot 8$ and $36.4 \%$ of the total detected amounts for the tissues surveyed, respectively. The present results are similar to other studies indicating that $\beta$-carotene is primarily stored in the liver in animals ${ }^{(40,41)}$, but primarily stored in the adipose tissue in humans ${ }^{(42,43)}$. Unfortunately, little is known about carotenoid distribution in other tissues, or the factors that influence this distribution. Statistically significant increases in tissue concentrations with higher $\beta$-cryptoxanthin intake were observed in many of the tissues that we studied, including the liver and kidneys, as well as the components of the digestive tract such as the small and large intestine. $\beta$-Cryptoxanthin concentrations increased in adipose tissue over baseline, but the changes were not significant. This may be an artifact of our sampling method since we did not excise and measure all adipose stores in the gerbil. Only abdominal adipose tissue was sampled in the present study, and adipose carotenoid composition can vary with the area of the body from which it was obtained $^{(38)}$. Thus, our values may not be representative of all adipose tissue. Alternatively, these results may suggest that $\beta$-cryptoxanthin uptake into adipose tissue is influenced by physiological mechanisms. For example, $\beta$-cryptoxanthin may be stored first in the liver, where its release is controlled. Alternatively, its absorption into adipose tissue may be saturable. 


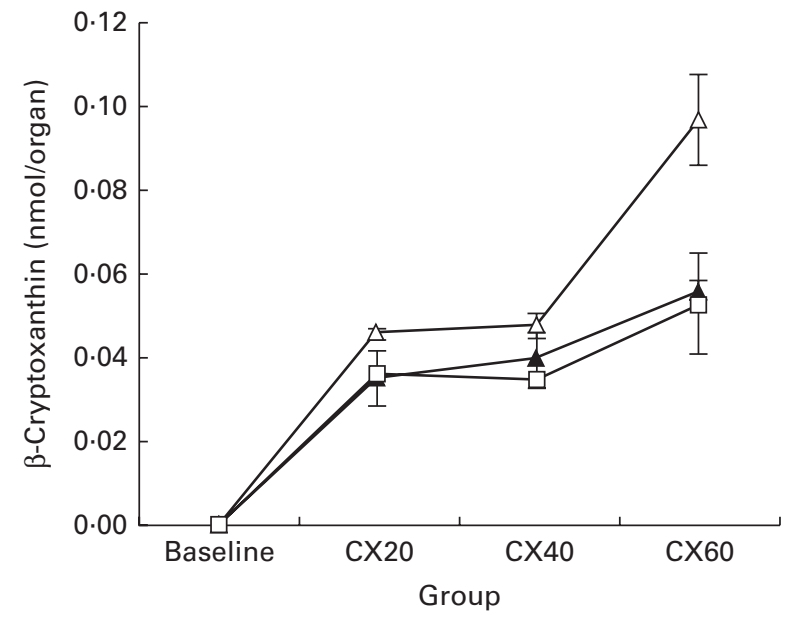

Fig. 1. Change in tissue concentration with varying intake of $\beta$-cryptoxanthin in the small intestine $\left(\triangle_{-}\right)$, caecum $\left(-\triangle_{-}\right)$and large intestine $(-\square)$. Values are means for baseline $(n 5)$ and for treatment groups $(n 8)$, with their standard errors represented by vertical bars. CX20, gerbil group fed $20 \mu \mathrm{g} \beta$-cryptoxanthin/d; CX40, gerbil group fed $40 \mu \mathrm{g} \beta$-cryptoxanthin/d; CX60, gerbil group fed $60 \mu \mathrm{g} \beta$-cryptoxanthin/d.

The apparent lack of a response to dietary intake for vitamin A might be due to the consumption of high concentrations of vitamin A by the gerbils in their pre-study and the acclimatisation period feed. Vitamin A concentrations were high in gerbil tissues at the beginning of the study and remained high in all the groups despite the fact that the study diet contained no preformed vitamin A. This might mean that the intake of $\beta$-cryptoxanthin was sufficient to sustain vitamin A tissue concentrations. However, it may also have been a result of the efficient homeostatic control of vitamin A stores in the body ${ }^{(44)}$. The vitamin A response tested in the present study included retinol and retinyl esters, but did not measure retinoic acid, a metabolite of $\beta$-cryptoxanthin, with biological activity of vitamin A found in low concentrations in biological tissues $^{(41,42)}$. Greater liver vitamin A stores in Mongolian gerbils are associated with decreased vitamin A bioconversion and consequently increased absorption of intact $\beta$-cryptoxanthin ${ }^{(45)}$. This occurred when gerbil retinol stores were $400 \mathrm{nmol} / \mathrm{g}^{(46,47)}$, an amount 6-fold less than that which was found in our gerbils.

The presence of $\beta$-cryptoxanthin in the entire digestive tract supports studies indicating that carotenoid absorption occurs not only in the small intestine, but in the caecum and large intestine as well (Fig. 1) ${ }^{(48,49)}$. The present results suggest that $\beta$-cryptoxanthin concentrations in these tissues are saturable (Fig. 2). $\beta$-Cryptoxanthin concentrations were not significantly different between the CX40 and CX60 groups except in the pancreas and intestines. In these tissues, there was a significant increase between the CX40 and CX60 groups. Although intestinal absorption of carotenoids had long been considered to occur by passive diffusion, research has now indicated that $\beta$-cryptoxanthin absorption may be facilitated by interaction with the enterocyte apical membrane transporter scavenger receptor class $\mathrm{B}$ type I protein, an epithelial transporter also involved in cholesterol uptake ${ }^{(50)}$. Saturation has been shown to occur in Caco-2 monolayers at concentrations equivalent to a $100 \mathrm{mg}$ dose of $\beta$-carotene in human subjects ${ }^{(51)}$. When we translated the amounts of $\beta$-cryptoxanthin consumed by the gerbils to humans based on their body weights, we estimated that the CX20, CX40 and CX60 groups would have consumed 31, 61 and $92 \mathrm{mg} \beta$-cryptoxanthin, respectively. The present results suggest that $\beta$-cryptoxanthin may be saturable up to $61 \mathrm{mg}$ and absorbed by passive diffusion at higher concentrations. However, since the average daily intake of $\beta$-carotene in humans is $1-2 \mathrm{mg}^{(52)}$, the consumption of doses comparable with that which we tested is uncommon.

Over $90 \%$ of $\beta$-cryptoxanthin excretion (probably a combination of unabsorbed and recycled $\beta$-cryptoxanthin) was through the faeces. This has also been observed for other carotenoids such as $\beta$-carotene and lutein, where most excretion occurs in the faeces ${ }^{(53)}$. An increase in the excretion of $\beta$-cryptoxanthin in the faeces was observed as the intake of $\beta$-cryptoxanthin increased.

Interesting observations were the absence of detectable concentrations of $\beta$-cryptoxanthin in the brain and eyes and its presence in only the highest dose group within the pancreas. It is possible that $\beta$-cryptoxanthin concentrations in the gerbil brain were lower than our limits of detection, since it has previously been identified in the human brain $^{(37)}$. However, there is no evidence in the past studies of $\beta$-cryptoxanthin in the eyes. This may suggest that not all xanthophylls are absorbed in ocular tissues or affect ocular function $^{(54)}$. Thus, there may be an active transport in the eye specific for lutein and zeaxanthin, although recent research has suggested that astaxanthin may have a role as well $^{(55)}$. The presence of $\beta$-cryptoxanthin in the pancreas at only high dosages may indicate that this is not a common storage area for $\beta$-cryptoxanthin and, instead, is only utilised during periods of excess intake.

The presence of retinoids in all of the tissues tested was expected ${ }^{(56)}$. Vitamin A is a ubiquitous compound in the body, with functions such as gene expression, vision and immunity in numerous tissues. Vitamin A stores did not decrease significantly in the present study despite the fact

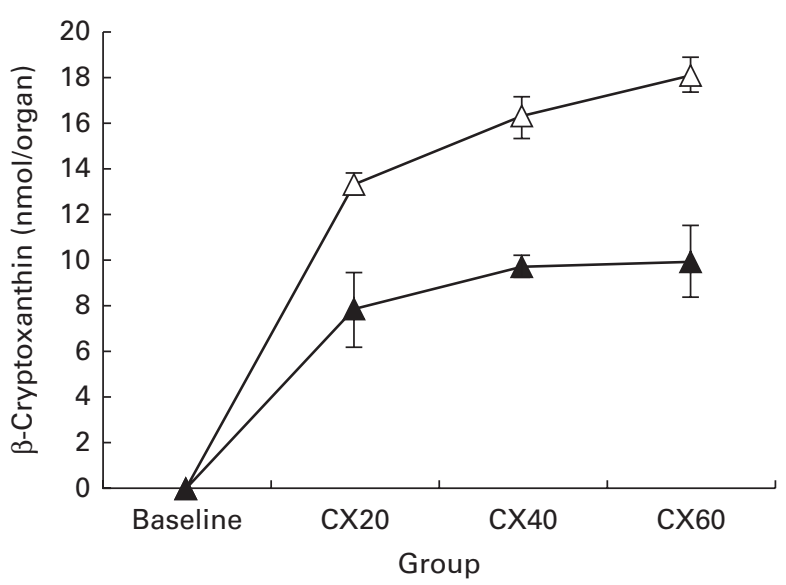

Fig. 2. Change in tissue concentration with varying intake of $\beta$-cryptoxanthin in the liver $\left(-\triangle_{-}\right)$and adipose $(-)$. Values are means $(n 5)$ for baseline and $(n 8)$ for treatment groups, with their standard errors represented by vertical bars. CX20, gerbil group fed $20 \mu \mathrm{g} \beta$-cryptoxanthin/d; CX40, gerbil group fed $40 \mu \mathrm{g} \beta$-cryptoxanthin/d; CX60, gerbil group fed $60 \mu \mathrm{g} \beta$-cryptoxanthin/d. 
that gerbils were fed a vitamin A-depleted diet for $21 \mathrm{~d}$. This is probably due to the long half-life of vitamin A in the body. However, $\beta$-cryptoxanthin might have helped maintain vitamin A stores, since it can form vitamin A. The treatment group that received the greatest amount of $\beta$-cryptoxanthin maintained liver vitamin A stores, while the groups that received 20 and $40 \mu \mathrm{g} \beta$-cryptoxanthin appeared to lose $14 \cdot 2$ and $3 \cdot 1 \%$ of their vitamin A stores, respectively. The slight decrease of vitamin A in the CX20 group may have been due to the formation of active retinol and retinoic acid metabolites in the body, although one study has reported that $\beta$-cryptoxanthin might also be capable of activating retinoic acid receptors ${ }^{(57)}$. Thus, the present results support other studies $(8,34,58)$ showing that $\beta$-cryptoxanthin might maintain or improve vitamin A stores in gerbils. Vitamin A was maintained or increased in several other tissues as well.

$\beta$-Cryptoxanthin apocarotenoids, such as $\beta$-apo- $10^{\prime}$ carotenal and $3-\mathrm{OH}-\beta$-apo- $10^{\prime}$-carotenal, have been detected in tissue cultures ${ }^{(28)}$. We attempted to detect the presence of some of their known metabolites in the gerbil liver. However, we did not detect these compounds in our samples. It may be that the size of our sample was too small, or that these metabolites may have been present only briefly after every meal. The potential $\beta$-cryptoxanthin metabolites 3-hydroxyretinol and 3,4-didehydroretinol were also not detected. These compounds are typically seen in freshwater fish ${ }^{(29,59,60)}$, which synthesise them from lutein- and cryptoxanthin-containing algae, or when they are consumed directly $^{(61)}$. These metabolites have only been previously detected in animals other than fish after they were consumed directly.

The results of the present study indicate that $\beta$-cryptoxanthin is present in numerous tissues within the body, and that it appears to be absorbed at least in part by an active transport mechanism. However, $\beta$-cryptoxanthin metabolites other than vitamin A might be rare or transitory. Future studies, including those utilising isotopic tracers, to investigate the metabolism of $\beta$-cryptoxanthin with respect to retinol, retinoic acid and apocarotenoids are necessary. These studies might use a longer depletion period for vitamin A, or a negative control group, all of which would increase our insight into the absorption and metabolism of this carotenoid.

\section{Acknowledgements}

We thank Chloe Dupertuis and Terry Neidlinger of the USDA WHNRC for their laboratory assistance during the study, Reina Engle-Stone of the UC Davis Department of Nutrition and John Newman and Theresa Pedersen of the USDA WHNRC for assistance with the procedure and sample analysis planning, Sherri Goss of the UC Davis Campus Veterinary Assistance for gerbil handling instruction, Rick Torres of Ventura Coastal for providing the tangerine concentrate used in the study, and Lacey Baldiviez and Jan Peerson of the UC Davis Department of Nutrition for assistance with the statistical analyses of the data.

The present study was funded by the USDA WHNRC in-house funds and a Henry A. Jastro Research Scholarship
Award, University of California, Davis. The funder did not contribute to the study design, management, analysis or interpretation of this article.

The authors' contributions were as follows: M. R. L. F. conducted the research, analysed the data and wrote the paper; C. Z. assisted with the extraction of tissues and performed the analysis of the data; B. J. B. designed the research, analysed the data, wrote the paper and had primary responsibility for the final content. All authors read and approved the final version of the paper.

The authors have no conflicts of interest.

\section{References}

1. Turner T, Burri BJ \& La Frano MR (2012) Beta-cryptoxanthin: a vitamin A-forming carotenoid. In Carotenoids: Properties, Effects and Diseases, pp. 331-354 [M Yamaguchi, editor]. Hauppauge, NY: Nova Science Publishers, Inc.

2. Fu HF, Xie BJ, Fan G, et al. (2010) Effect of esterification with fatty acid of $\beta$-cryptoxanthin on its thermal stability and antioxidant activity by chemiluminescence method. Food Chem 122, 602-609.

3. Tanaka T, Tanaka M \& Kuno T (2012) Cancer chemoprevention by citrus pulp and juices containing high amounts of $\beta$-cryptoxanthin and hesperidin. J Biomed Biotechnol 2012, $1-10$

4. Tanaka T, Kohno H, Murakami M, et al. (2000) Suppression of azoxymethane-induced colon carcinogenesis in male F344 rats by mandarin juices rich in beta-cryptoxanthin and hesperidin. Int J Cancer 88, 146-150.

5. Liu C, Bronson RT, Russell RM, et al. (2011) $\beta$-Cryptoxanthin supplementation prevents cigarette smoke-induced lung inflammation, oxidative damage, and squamous metaplasia in ferrets. Cancer Prev Res 4, 1255-1266.

6. Iskandar AR, Liu C, Smith DE, et al. (2013) Beta-cryptoxanthin restores nicotine-reduced lung SIRT1 to normal levels and inhibits nicotine-promoted lung tumorigenesis and emphysema in A/J mice. Cancer Prev Res 6, 309-320.

7. Yamaguchi M (2012) Role of carotenoid beta-cryptoxanthin in bone homeostasis. J Biomed Sci 19, 36.

8. Davis C, Jing H, Howe JA, et al. (2008) $\beta$-Cryptoxanthin from supplements or carotenoid-enhanced maize maintains liver vitamin A in Mongolian gerbils (Meriones unguiculatus) better than or equal to $\beta$-carotene supplements. Br J Nutr 100, 786-793.

9. Turner T, Burri BJ, Jamil KM, et al. (2013) The effects of daily consumption of $\beta$-cryptoxanthin-rich tangerines and $\beta$-carotene-rich sweet potatoes on vitamin $\mathrm{A}$ and carotenoid concentrations in plasma and breast milk of Bangladeshi women with low vitamin A status in a randomized controlled trial. Am J Clin Nutr 98, 1200-1208.

10. Burri BJ, Chang JST \& Neidlinger TR (2011) Betacryptoxanthin- and alpha-carotene-rich foods have greater apparent bioavailability than beta-carotene-rich foods in Western diets. Br J Nutr 105, 212-219.

11. Burri BJ, Chang JST \& Turner T (2011) Citrus can help prevent vitamin A deficiency in developing countries. Cal Ag 65, 130-135.

12. Dhuique-Mayer C, Borel P, Reboul E, et al. (2007) $\beta$-Cryptoxanthin from Citrus juices: assessment of bioaccessibility using an in vitro digestion/Caco-2 cell culture model. Br J Nutr 97, 883-890.

13. Castenmiller JJM \& West CE (1998) Bioavailability and bioconversion of carotenoids. Annu Rev Nutr 18, 19-38. 
14. O'Connell OF, Ryan L \& O'Brien NM (2007) Xanthophyll carotenoids are more bioaccessible from fruits than dark green vegetables. Nutr Res 27, 258-264.

15. de Pee S, West CE \& Permaesih D (1998) Orange fruit is more effective than are dark-green, leafy vegetables in increasing serum concentrations of retinol and $\beta$-carotene in schoolchildren in Indonesia. Am $J$ Clin Nutr 68 , 1058-1067.

16. Tomita Y, Senanayake GVK, Yosioka T, et al. (2002) Conversion of intravenously administered beta-cryptoxanthin to a beta-carotene-like compound in mouse lung. J Nutr Sci Vitaminol 48, 443-447.

17. Surai PF, Royle NJ \& Sparks NHC (2000) Fatty acid, carotenoid and vitamin A composition of tissues of free living gulls. Comp Biochem Physiol A Mol Integr Physiol 126, 387-396.

18. House WA, Apgar J \& Smith JC (1997) The gerbil: a model for studying the metabolism of beta-carotene and minerals. Nutr Res 17, 1293-1302.

19. Lee CM, Lederman JD, Hofmann NE, et al. (1998) The Mongolian gerbil (Meriones unguiculatus) is an appropriate animal model for evaluation of the conversion of $\beta$-carotene to vitamin. J Nutr 128, 280-286.

20. Pollack J, Campbell JM, Potter SM, et al. (1994) Mongolian gerbils (Meriones-unguiculatus) absorb $\beta$-carotene intact from test meal. J Nutr 124, 869-873.

21. Vankuijk FJ, Handelman GJ \& Dratz EA (1985) Rapid analysis of the major classes of retinoids by step gradient reversedphase high-performance liquid-chromatography using retinal (O-ethyl) oxime derivatives. J Chromatogr 348, 241-251.

22. Breithaupt DE, Weller P, Wolters M, et al. (2003) Plasma response to a single dose of dietary $\beta$-cryptoxanthin esters from papaya (Carica papaya L.) or non-esterified $\beta$-cryptoxanthin in adult human subjects: a comparative study. Br J Nutr 90, 795-801.

23. Rodriguez-Amaya DB \& Kimura M (2004) HarvestPlus Handbook for Carotenoid Analysis. HarvestPlus Technical Monograph 2. Washington, DC and Cali: IFPRI and CIAT.

24. Rajendran V, Pu YS \& Chen BH (2005) An improved HPLC method for determination of carotenoids in human serum. J Chromatogr B Analyt Technol Biomed Life Sci 824, 99-106.

25. Howe JA, Maziya-Dixon B \& Tanumihardjo SA (2009) Cassava with enhanced $\beta$-carotene maintains adequate vitamin A status in Mongolian gerbils (Meriones unguiculatus) despite substantial cis-isomer content. Br J Nutr 102, 342-349.

26. Turner T \& Burri BJ (2012) Rapid isocratic HPLC method and sample extraction procedures for measuring carotenoid, retinoid, and tocopherol concentrations in human blood and breast milk for intervention studies. Chromatographia $\mathbf{7 5}$, 241-252.

27. Valentine AR \& Tanumihardjo SA (2004) Adjustments to the modified relative dose response (MRDR) test for assessment of vitamin A status minimize the blood volume used in piglets. J Nutr 134, 1186-1192.

28. Mein JR, Dolnikowski GG, Ernst H, et al. (2011) Enzymatic formation of apo-carotenoids from the xanthophyll carotenoids lutein, zeaxanthin and $\beta$-cryptoxanthin by ferret carotene- $9^{\prime}, 10^{\prime}$-monooxygenase. Arch Biochem Biophys 506, $109-121$.

29. La Frano MR \& Burri BJ (2013) Analysis of retinol, 3-hydroxyretinol, and 3,4-didehydroretinol in North-American farm-raised freshwater fish liver, muscle, and feed. Aquac Nutr (In the Press).

30. Iowa State University Institutional Animal Care and Use Committee (2010) Blood collection guidelines. http://www. compliance.iastate.edu/iacuc/policies/docs/blood-collectionguidelines.pdf (accessed March 2013).

31. Xu DL \& Wang DH (2010) Fasting suppresses $\mathrm{T}$ cellmediated immunity in female Mongolian gerbils (Meriones unguiculatus). Comp Biochem Physiol A Mol Integr Physiol 155, 25-33.

32. Preedy VR (2012) Vitamin A and Carotenoids: Chemistry, Analysis, Function and Effects. Cambridge: The Royal Society of Chemistry.

33. Breithaupt DE, Yahia EM \& Velazquez FJ (2007) Comparison of the absorption efficiency of $\alpha$ - and $\beta$-cryptoxanthin in female Wistar rats. Br J Nutr 97, 329-336.

34. Arscott SA, Howe JA, Davis CR, et al. (2010) Carotenoid profiles in provitamin A-containing fruits and vegetables affect the bioefficacy in Mongolian gerbils. Exp Biol Med 235, 839-848.

35. Wingerath T, Stahl W \& Sies H (1995) $\beta$-Cryptoxanthin selectively increases in human chylomicrons upon ingestion of tangerine concentrate rich in $\beta$-cryptoxanthin esters. Arch Biochem Biophys 324, 385-390.

36. Granado-Lorencio F, Donoso-Navarro E, Sánchez-Siles LM, et al. (2011) Bioavailability of $\beta$-cryptoxanthin in the presence of phytosterols: in vitro and in vivo studies. J Agric Food Chem 59, 11819-11824.

37. Craft NE, Haitema TB, Garnett KM, et al. (2004) Carotenoid, tocopherol, and retinol concentrations in elderly human brain. J Nutr Health Aging 8, 156-162.

38. Chung HY, Ferreira ALA, Epstein S, et al. (2009) Site-specific concentrations of carotenoids in adipose tissue: relations with dietary and serum carotenoid concentrations in healthy adults. Am J Clin Nutr 90, 533-539.

39. Otten JJ, Hellwig JP \& Meyers LD (2006) Dietary Reference Intakes: The Essential Guide to Nutrient Requirements. Food and Nutrition Board, pp. 211-217. Washington, DC: The National Academies Press.

40. Gugger ET, Bierer TL, Henze TM, et al. (1992) $\beta$-Carotene uptake and tissue distribution in ferrets (Mustela putorius furo). J Nutr 122, 115-119.

41. Ribaya-mercado JD, Holmgren SC, Fox JG, et al. (1989) Dietary $\beta$-carotene absorption and metabolism in ferrets and rats. J Nutr 119, 665-668.

42. Bendich A \& Olson JA (1989) Biological actions of carotenoids. FASEB J 3, 1927-1932.

43. Olson JA (1984) Serum levels of vitamin A and carotenoids as reflectors of nutritional-status. J Natl Cancer Inst $\mathbf{7 3}$ 1439-1444.

44. Tanumihardjo SA (2011) Vitamin A: biomarkers of nutrition for development. Am J Clin Nutr 94, 658S-665S

45. Tanumihardjo SA (2008) Food-based approaches for ensuring adequate vitamin A nutrition. Compr Rev Food Sci Food Safety 7, 373-381.

46. Dosti MP, Mills JP, Simon PW, et al. (2006) Bioavailability of $\beta$-carotene $(\beta C)$ from purple carrots is the same as typical orange carrots while high- $\beta C$ carrots increase $\beta C$ stores in Mongolian gerbils (Meriones unguiculatus). Br J Nutr 96, 258-267.

47. Howe JA \& Tanumihardjo SA (2006) Carotenoid-biofortified maize maintains adequate vitamin A status in Mongolian gerbils. J Nutr 136, 2562-2567.

48. Goñi I, Serrano J \& Saura-Calixto F (2006) Bioaccessibility of $\beta$-carotene, lutein, and lycopene from fruits and vegetables. J Agric Food Chem 54, 5382-5387.

49. Escaron AL \& Tanumihardjo SA (2006) Absorption and transit of lutein and $\beta$-carotene supplements in the Mongolian gerbil (Meriones unguiculatus). Int J Vitam Nutr Res $\mathbf{7 6}$, $315-323$ 
50. During A, Dawson HD \& Harrison EH (2005) Carotenoid transport is decreased and expression of the lipid transporters SR-BI, NPC1L1, and ABCA1 is downregulated in Caco-2 cells treated with ezetimibe. J Nutr 135, 2305-2312.

51. During A, Hussain MM, Morel DW, et al. (2002) Carotenoid uptake and secretion by CaCo-2 cells: $\beta$-carotene isomer selectivity and carotenoid interactions. J Lipid Res 43, 1086-1095.

52. Grune T, Lietz G, Palou A, et al. (2010) Beta-carotene is an important vitamin A source for humans. I Nutr $\mathbf{1 4 0}$, 2268S-2285S

53. Ho CC, de Moura FF, Kim SH, et al. (2009) A minute dose of ${ }^{14} \mathrm{C}-\beta$-carotene is absorbed and converted to retinoids in humans. J Nutr 139, 1480-1486.

54. Ahmed SS, Lott MG \& Marcus DM (2005) The macular xanthophylls. Surv Ophthalmol 50, 183-193.

55. Cort A, Ozturk N, Akpinar D, et al. (2010) Suppressive effect of astaxanthin on retinal injury induced by elevated intraocular pressure. Regul Toxicol Pharmacol 58, 121-130.

56. D'Ambrosio DN, Clugston RD \& Blaner WS (2011) Vitamin A metabolism: an update. Nutrients 3, 63-103.
57. Matsumoto A, Mizukami H, Mizuno S, et al. (2007) $\beta$-Cryptoxanthin, a novel natural RAR ligand, induces ATPbinding cassette transporters in macrophages. Biochem Pharm 74, 121-130.

58. Mills JP, Simon PW \& Tanumihardjo SA (2007) $\beta$-Carotene from red carrot maintains vitamin A status, but lycopene bioavailability is lower relative to tomato paste in Mongolian gerbils. J Nutr 137, 1395-1400.

59. Barua AB, Das R \& Verma K (1977) Occurrence of 3-hydroxyretinol in freshwater fish Bagarius bagarius and Wallago attu-isolation and synthesis. Biochem J 168, 557-564.

60. Doyon C, Boileau S, Fortin R, et al. (1998) Rapid HPLC analysis of retinoids and dehydroretinoids stored in fish liver: comparison of two lake sturgeon populations. J Fish Biol 53, 973-986.

61. Tanumihardjo SA, Muherdiyantiningsih, Permaesih D, et al. (1994) Assessment of the vitamin-A status in lactating and nonlactating, nonpregnant Indonesian women by use of the modified-relative-dose-response (MRDR) test. $\mathrm{Am} \mathrm{J}$ Clin Nutr 60, 142-147. 